\title{
SURVIVING POVERTY: Stress and Coping in the Lives of Housed and Homeless Mothers
}

\author{
Victoria L. Banyard, Ph.D., and Sandra A. Graham-Bermann, Ph.D.
}

Stress, coping, and depressed mood were examined in a sample of 64 homeless mothers and a comparison group of 59 housed low-income mothers. Homeless mothers reported significantly higher levels of stress and depression, as well as greater use of avoidant and active-cognitive coping strategies, than did the housed mothers. Within-group analyses revealed an association between greater use of avoidant strategies and higher levels of reported depression for both groups. Implications for research and program development are discussed.

$\mathrm{E}$ stimates of how many people are homeless vary, but the number is generally agreed to be increasing, particularly of homeless families (DiBlasio \& Belcher, 1995; Link et al., 1994; Toro et al., 1995). The homeless are also known to be heterogeneous, and research has documented both gender differences and differences between single adults and those who have custody of children (Bassuk. 1993a; Burt \& Cohen, 1989; DiBlasio \& Belcher, 1992, 1995; Hagen, 1987; North \& Smith, 1993; Roth, Toomey, \& First, 1992; Toro et al., 1995). This heterogeneity has hampered attempts at moving beyond descriptive and demographic surveys toward theoretical models of homelessness (Milburn \& D'Ercole, 1991). Because they are flexible in allowing and accounting for group differences, theories of stress and coping have been proposed as a useful framework for creating such models by exploring factors that may mediate the antecedents of homelessness and its effects on emotional well-being (Milburn \& D'Ercole, 1991). To date, however, there has been little empirical testing of coping theories among homeless women (Koegel, Burnam, \& Farr, 1990; Milburn \& D'Ercole, 1991; Shinn \& Weitzman, 1990). The study reported here sought to expand our understanding of homelessness by examining the stress and coping process among a sample of homeless mothers and a comparison group of housed low-income mothers.

Researchers, policymakers, and service providers working with the homeless have become concerned about the intersection between homelessness and emotional distress. While women in families who are homeless report less use of alcohol and fewer psychi-

A revised version of a paper submitted to the Journal in February 1997. Work was supported by funds from the University of Michigan Rackham Graduate School Thesis Grant and Dissertation Fellowship programs, by a Woodrow Wilson National Fellowship Foundation Dissertation Grant in Women's Studies, and by National Institute of Mental Health Training Grant 5-T32-MH15161. Authors are at: Department of Psychology, University of New Hampshire, Durham (Banyard); and Department of Psychology, University of Michigan, Ann Arbor (Graham-Bermann). 
atric problems than do single homeless adults, they nevertheless have higher rates for these problems than do housed lowincome mothers (Buckner, Bassuk, \& Zima, 1993; Ingram, Corning, \& Schmidt, 1996; Robertson, 1991; Wagner \& Perrine, 1994; Weitzman, Knickman, \& Shinn, 1992). Homeless families face a number of problems that could lead to high levels of emotional distress for both parents and children (Banyard, 1995; Bassuk, 1993b; Burt \& Cohen, 1989; Goodman, Saxe, \& Hanvey, 1991; Hausman \& Hammen, 1993; Masten, Miliotis, Graham-Bermann, Ramirez, \& Neeman, 1993; Rescorla, Parker, \& Stolley, 1991). For example, a review by Milburn and D'Ercole (1991) documented an array of stressors faced by homeless mothers that included housing instability, victimization, employment difficulties, and chronic poverty. Goodman, Saxe, and Harvey (1991) described the condition of being homeless as traumatic in itself and as carrying negative consequences for mental health.

Mental health problems may also be important precursors to homelessness. Bassuk (1993b) and Brooks and Buckner (1996) discussed such key macro-level problems as low-wage employment, low welfare payments, and shortages of low-income housing that produce the context for the poverty of which homelessness is an extreme example. While this context creates distress, research has also suggested that factors such as depression or substance abuse may hamper survival efforts among scarce resources, making individuals more vulnerable to homelessness. Bassuk (1993b) and others (Buckner et al., 1993; Robertson, 1991) have discussed the need for greater understanding of these connections, and of factors, such as coping, that mediate them.

\section{STRESS AND COPING THEORIES}

Stress and coping theory has been proposed as a paradigm for understanding links between the condition of homelessness and mental health (Milburn \& D'Ercole, 1991). Stress has been examined more generally in terms of both life events and chronic strains (Pearlin, 1989; Peters \& Massey, 1983; Wheaton, 1994), and has been defined and measured in a variety of ways (Aldwin, 1994; Hobfoll, 1989; Pearlin, 1989; Turner, Wheaton, \& Lloyd 1995). Homelessness is undoubtedly a stressor by any definition; indeed, Milburm and D'Ercole (1991) defined it as both the result of a variety of stressors (e.g., eviction, unemployment, victimization) and as a stressor in itself. Work in the area of stress theory has documented links between high stress and such mental health problems as depression (Monroe \& McQuaid, 1994; Turner et al, 1995; Wheaton, 1994).

The relationship between stress and mental health, however, is influenced by intervening processes like coping (Avison \& Gotlieb, 1994; Billings \& Moos, 1981; Folkman \& Lazarus, 1980; Fondacaro \& Moos, 1989; Holahan \& Moos, 1987a, 1987b; Lazarus \& Folkman, 1984; Pearlin \& Schooler, 1978). Folkman and Lazarus (1980) and others (Billings \& Moos, 1981; Holohan \& Moos, 1987a; Pearlin \& Schooler, 1978) have defined coping not as a stable personality trait, but as an individual response to situations seen as stressful and an interaction between person and environment that may change across situations and contexts. Earlier research on coping found that an individual may use a variety of strategies for coping with any one situation (Folkman \& Lazarus, 1980; Holohan \& Moos, 1987a; Lykes, 1983; McAdoo, 1986; Pearlin \& Schooler, 1978; Stone \& Neale, 1984). These strategies may be to act directly on the problem and work at solving it; or they may be more cognitively or emotionally based, and seek to alter the meaning of the situation or the level of one's emotional response (Folkman \& Lazarus, 1980). The use of certain types of coping, particularly the use of avoidant strategies that seek to escape dealing with the problem, have been associated with greater symptomatology such as depression (Fondacaro \& Moos, 1989; Holohan \& Moos, 1987b), while more direct 
problem-solving strategies appear to be associated with stress resistance over time (Holohan \& Moos, 1990). To date, however, there have been few research efforts to understand coping among homeless mothers.

The study reported here was exploratory in nature and had two primary goals. The first was to examine links among stress, coping, and depression in a sample of homeless mothers, using conventional measures of these constructs from the research literature. At the same time, the possibility of replicating findings from other coping research in a sample of homeless mothers (a group not often represented in prior research or in the development of coping measures) was tested. From the coping literature, it was hypothesized that variations in depression levels in this group would be partially explained by differences in exposure to stressful life events and in coping strategies used; specifically, that higher depression levels would be associated with higher stress levels and greater use of avoidant coping strategies.

The second goal was to compare the sample of homeless families to a group of housed low-income families. Work by Belle (1982; 1990) and others (Olson, Kieschnick, Banyard, \& Ceballo, 1994; Turner, et. al., 1995) has documented high levels of depression among low-income mothers. It was hypothesized that homeless mothers would report higher levels of stress and depression than the housed sample, but that the patterns of association among stress, coping, and depression would be the same for the two groups: i.e., high levels of stress and avoidance coping would be related to depression for both groups, although the scores of the homeless group would be more extreme.

\section{METHOD}

\section{Participants}

Mothers with at least one child below the age of 12 formed the sample and comparison groups. The sample group consisted of 64 women residing with their children in one of three temporary family emergency shel- ters in three small Midwestern cities. The comparison group consisted of 59 lowincome mothers residing in their own home or apartment and receiving public assistance at the time of the interview. TABLE 1 provides a list of sample demographics for both groups. The number of participants identifying themselves as Asian, Latina, or Native-American was so small that they were grouped with African-American women. Minority women formed more than half of the housed and well over three-quarters of the homeless groups. Analysis ( $t$-test and chi-square) revealed that the sample and comparison groups did not differ in number of children, education, or marital status. As might be expected, the homeless women reported a significantly lower income than did the housed mothers-a median income of $\$ 463$ and $\$ 650$ per month, respectively. There were also group differences in age and ethnicity: the housed group was slightly older and contained proportionately fewer minority women. Eight women in the housed sample (14\%) reported that they had previously spent time in a homeless shelter.

\section{Procedure}

Homeless participants for this study (which was part of a larger collaborative study of homeless families) were drawn

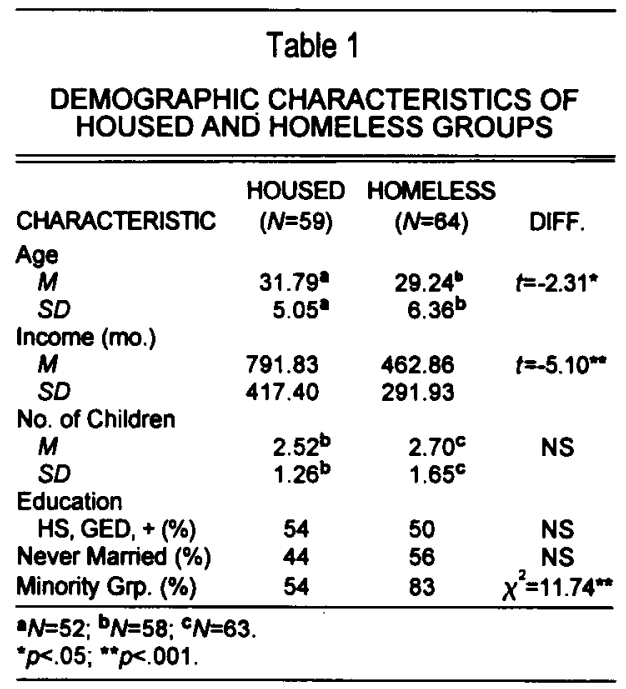


from three independent temporary shelters for women and families. These shelters screened residents prior to admission and did not accept women who were actively abusing substances. Sample members were recruited through shelter staff, who invited all women with custody of at least one child below the age of 12 to be part of a survey of families. Only one mother failed to complete the interview after the study started.

The comparison group of housed women was recruited through flyers at offices of the Department of Social Services and in low-income housing developments. It invited mothers to join a survey of how families in different situations dealt with various daily problems, asking them to phone the research lab for an appointment. It was not possible to calculate the participation rate for the community sample, but only one woman declined to participate after receiving further information about the project. Two participants were dropped from the analyses because of extensive missing data.

Each participant was interviewed for several hours, housed women in their homes, homeless women in a private office at the shelter. (Their children were interviewed independently for a separate part of the study.) Interviews were conducted by the current investigators and by female graduate students. The women were paid $\$ 15$ for their participation.

\section{Measures}

Each woman was asked to complete a number of questionnaires that included the standardized measures of stress, coping, and depression used in the current analyses. The homeless mothers also took part in a larger semi-structured, qualitative interview. Qualitative analyses of these data are presented elsewhere (Banyard, 1995; Banyard \& Graham-Bermann, 1995).

Demographic information. The interview contained questions about age, ethnicity, monthly income, marital status, highest level of education, and number of chil- dren. Given the narrow range of variability on several questions, the education, marital status, and ethnicity factors were dummycoded in the analyses of the data. Missing data for six participants on the income variable was treated by using group mean substitutions.

Stress. Recent stress was assessed using the African-American Women's Stress Scale developed by Watts-Jones (1991) as a more accurate measure of stressful life events in a sample of African-American women in the community. It is a 100 -item checklist of possible stressful events experienced over the past six weeks. The range of incidents includes interpersonal and financial difficulties, as well as incidents of racism. Scores are obtained by summing the number of reported incidents., and for the sample as a whole they ranged from 4 to 62 . Internal consistency for the current sample was .87 .

Coping responses. Coping was measured using 32 items from the Health and Daily Living Form (HDLF) that Moos, Cronkite, and Finney (1984) developed using community and clinical samples. Participants are asked to describe a significant recent stressor and to indicate on a four-point scale their use of each of 32 strategies. Scores are obtained by summing responses to questions within each of three methods of coping: active-behavioral, active-cognitive, and avoidant. The first strategy deals directly with the problem, the second manages appraisal of the stressful event, and the third evades confronting the problem. The first two comprise what Holohan and Moos (1990) have described as "approach coping" strategies. The 13 active behavioral strategies on the HDLF include such items as "Made a plan of action and followed it" and "Tried to find out more about the situation." Scores on these items for the whole sample had a range of 10-37. The 11 active-cognitive strategies on the HDLF include such items as "Prayed for guidance or strength," "Considered several alternatives for handling the problem," and 
"Tried to see the positive side of the situation." Scores on these items for the sample as a whole had a range of 7-32. The eight avoidant HDLF strategies include such items as, "Kept my feelings to myself," "Refused to believe that it happened," and "Tried to reduce tension by smoking more." Sample scores on the avoidant index had a range of 0-22. Cronbach's alpha was .59 for the active-behavioral index, .62 for the active-cognitive index, and .63 for the avoidant index.

Depressed mood. Emotional distress was assessed using the Center for Epidemiological Studies Depression (CES-D) scale. This is a 20-item scale developed to measure current depressive symptomatology in the community (Radloff, 1977; Weissman, Sholomskas, Pottenger, Prusoff, \& Locke, 1977). Respondents are asked to rate, on a four-point scale, how much they agreed with each of 20 statements (e.g., "I thought my life had been a failure") during the past week. Scores for the current sample had a range of 0-51. Cronbach's alpha for the current sample was .80 .

\section{RESULTS}

The first analysis examined levels of stress, coping, and depression in the homeless and housed groups to test the hypothesis that homeless mothers would report higher levels of stress and distress. A oneway (housing status) multivariate analysis of covariance (MANCOVA) was performed on five dependent variables: total stress, depression, and avoidant, active-cognitive, and active-behavioral coping. Ethnicity, age, and income were used as covariates, since they were either variables on which the homeless and housed groups differed significantly or demographics that were significantly related to the dependent variables. The independent variable was housing status (homeless or housed). TABLE 2 shows the results of this analysis. The overall MANCOVA for housing status was significant, $F(5,105)=5.50, p<.001$. The three covariates were also significant $F(15$,
Table 2

DIFFERENCES IN STRESS, COPING, AND DEPRESSED MOOD AS A FUNCTION OF HOUSING STATUS

\begin{tabular}{lrrl}
\hline \hline VARIABLE & HOUSED & HOMELESS & SIGNIF. \\
Depression & & & \\
$M$ & 17.86 & 28.29 & $p=.000$ \\
SD & 10.73 & 11.09 & \\
Total Stress Score & & & \\
$\quad M$ & 28.07 & 35.55 & $p=.002$ \\
$\begin{array}{l}\text { SD } \\
\text { Coping }\end{array}$ & 10.10 & 10.42 & \\
Active-cognitive & & & \\
$\begin{array}{l}M \\
\text { SD }\end{array}$ & 22.52 & 24.02 & $p=.999$ \\
Active-behavioral & 5.64 & 4.09 & \\
$M$ & 23.06 & 22.59 & $p=.954$ \\
SD & 5.63 & 5.74 & \\
Avoidant & & & \\
$M$ & 7.45 & 9.88 & $p=.003$ \\
SD & 4.39 & 4.19 & \\
\hline
\end{tabular}

$321)=2.49, p=.002$. Univariate analyses revealed significant differences between the homeless and housed mothers for three of the five dependent variables, but none for reported use of active-behavioral $[F(1,109)=$ $.000, p>.05]$ or active-cognitive $[F(1,109)=$ $.003, p>.05]$ coping. However, homeless mothers reported significantly higher stress scores $[F(1,109)=9.69, p=.002]$, higher depressed mood scores $[F(1,109)=19.60, p<$ $.001]$, and higher use of avoidant coping methods $[F(1,109)=9.36, p=.003]$ than did the housed mothers.

The second analysis explored these differences in more detail. A score of 16 on the CES-D has been cited in the literature as a marker that separates community and clinical samples (Comstock \& Helsing, 1976; Radloff, 1977; Weissman et al, 1977). In the current sample, $84 \%$ of the homeless mothers had depression scores above 16 , compared to $46 \%$ of the housed group $\left(X^{2}=\right.$ $20.35, p<.001$ ). An exploratory item analysis of the stress scale examined items that seemed to discriminate between the homeless and housed groups, and 28 were found to be more frequently endorsed by homeless participants. These included living in a high crime area, physical abuse by a partner, being a crime victim, inability to access social supports, family alcohol problems, and a variety of income problems 
Table 3

CORRELATIONS AMONG SCORES ON MEASURES OF STRESS, DEPRESSION, AND COPING METHODS FOR HOMELESS AND HOUSED GROUPS

\begin{tabular}{lccccc}
\hline \hline & & & \multicolumn{3}{c}{ COPING } \\
\cline { 4 - 6 } VARIABLE & STRESS & DEPRESSED & COGNITIVE & BEHAVIOR. & AVOIDANT \\
Stress & - & $0.40^{* *}$ & 0.08 & 0.04 & 0.04 \\
Depressed Mood & 0.20 & - & -0.00 & -0.17 & $0.35^{* * *}$ \\
Coping & & & & & $0.52^{* * *}$ \\
$\quad$ Active-cognitive & 0.15 & -0.06 & - & -05 \\
Active-behavioral & -0.20 & -0.01 & $0.29^{*}$ & -0.09 \\
Avoidant & -0.09 & $0.31^{*}$ & -0.06 & 0.01 & - \\
\hline
\end{tabular}

Note. Housed group appears below the diagonal.

" $\rho \leq .05 ; " * \leq .01$

such as overcrowded housing, being behind in paying bills, and being unable to afford necessities for one's children.

Further analyses examined relationships among stress, coping, and depression for the homeless and housed groups. Pearson product-moment correlations were computed among demographic variables and measures of stress, coping, and depressed mood for each group (see table 3). Among homeless participants, ethnicity was the only demographic variable significantly related to depressed mood, in that those who belonged to an ethnic minority reported lower rates of depression. Also in the homeless sample, older women reported lower usage of avoidant coping, none of the demographic variables was correlated with reported stress level, and higher depression scores were related to higher stress scores and greater use of avoidant coping. For the housed group, correlational patterns were somewhat different. Members of ethnic minority groups reported lower stress scores, and mothers with lower incomes reported higher stress scores and greater use of active-cognitive coping. Total stress scores were not significantly related to depression or coping for this group, although higher depression was significantly associated with greater use of avoidant coping.

Hierarchical multiple regression analyses were then used to further test withingroup relationships among stress, coping, and depression. TABLES 4 and 5 show the results for the homeless and housed groups, re- spectively. The demographic variable of ethnicity was entered on the first step, while stress and coping indices were entered on the second. Total stress scores contributed significantly to the variance in depression for the homeless sample, but not for the housed group. Avoidant coping scores contributed significantly to the variance in depression scores for both groups.

The final analytic step was to examine more closely the differing relationships between stress and depression for the two groups. It investigated whether the association between stress and coping was different for the two groups, given that on the bivariate level stress was significantly related to depression for the homeless but not the housed group. Procedures for testing moderating effects, as described by Baron and Kenny (1986) and Pedhazur and Schmelkin (1991), were used. The independent variable was housing status, the dependent variable was depression, and the moderator

\section{Table 4}

VARIABLES PREDICTING DEPRESSION IN HOMELESS MOTHERS $(N=64)$ : HIERARCHICAL REGRESSION ANALYSIS

\begin{tabular}{lccc}
\hline \hline $\begin{array}{l}\text { VARIABLE } \\
\text { Step 1 }\end{array}$ & $B$ & SE B & $B$ \\
$\quad$ Ethnicity & -8.27 & 3.49 & $-0.29^{*}$ \\
Step 2 & & & \\
$\quad$ Total stress score & 0.38 & 0.11 & $0.36^{* * *}$ \\
Active-behavioral coping & -0.37 & 0.24 & -0.19 \\
Active-cognitive coping & 0.25 & 0.33 & 0.10 \\
Avoidant coping & 0.80 & 0.27 & $0.32^{* *}$ \\
\hline
\end{tabular}

Note. $R^{2}=.08$ for Step 1; $\Delta R^{2}=.28$ for Step 2 (p<.001). *p<.05; "*ip<.01; ***p<.001. 


\section{Table 5}

VARIABLES PREDICTING DEPRESSION IN HOUSED LOW-INCOME MOTHERS ( $N=59$ ): HIERARCHICAL REGRESSION ANALYSIS

\begin{tabular}{lrcc}
\hline \hline VARIABLE & $B$ & SE B & $B$ \\
Step 1 & & & \\
$\quad$ Ethnicity & -3.48 & 2.85 & -0.16 \\
Step 2 & & & \\
$\quad$ Total stress score & 0.26 & 0.15 & 0.25 \\
Active-behavioral coping & 0.14 & 0.27 & 0.07 \\
Active-cognitive coping & -0.19 & 0.27 & -0.10 \\
Avoidant coping & 0.81 & 0.33 & $0.32^{*}$ \\
\hline Note. $R^{2}=.03$ for Step 1; $\Delta R^{2}=.13$ for Step 2(p=.10). \\
- $p<.05$.
\end{tabular}

was defined as stress scores. Moderator effects were tested by regressing housing status, stress scores, and a term representing the interaction of these variables on depression (see TABLE 6). The interaction term was not significant, indicating that there was no significant moderating effect of stress for this sample. Statistically, the slopes of the two equations were not significantly different from one another. The relationship between stress and depression did not appear to be significantly different for the housed and homeless groups. The statistically significant group differences were in mean stress and depressed mood scores, with the homeless sample showing more extreme values.

\section{DISCUSSION}

The current study used theories of stress and coping to understand variability in reported rates of depression among homeless mothers and between homeless and housed low-income mothers. Homeless mothers reported higher levels of stress and depressed mood than did the housed lowincome women. Analyses of the relationships among stress, coping, and depression revealed somewhat similar patterns within the two groups. Greater use of avoidant coping strategies was associated with higher depressive symptomatology in both groups. Levels of stress showed no significant differential related to depressed mood for either group except in degree, with homeless mothers showing higher levels of stress and depressed mood but a similar pattern of interaction. This suggests that while the stress and coping process may not be different for homeless and housed mothers, they experience it at different magnitudes. Such high levels of stress and depressive symptoms have important consequences not only for the well-being of homeless mothers, but also for that of their children, since the negative effects of such factors as maternal depression on children has been documented (Goldsmith \& Rogoff, 1995; Teti, Gelfand, Messinger, \& Isabella, 1995).

The pattern of results found in the present study is consistent with the literature on both the causes and the effects of homelessness. Previous findings have suggested that homelessness is associated with levels of stress and distress beyond the chronic strain more generally associated with living in poverty (Goodman et. al., 1991; Toro et. al., 1995). The current data support this view. Homeless mothers consistently reported a higher level of depressive symptoms and greater number of stressful events than did the comparison group of housed low-income women. In particular, the homeless sample more often cited the stress of being abused by a partner, behind in paying bills, or let down by a friend; having to live in another's home, overcrowded housing, or a dangerous neighborhood; unemployment; and inability to afford necessities. Homeless women more often cited extreme financial stress and problems with friends and family than did housed mothers. While this suggests that the differences between housed and homeless women is the degree of poverty with which they are

\begin{tabular}{|c|c|c|c|}
\hline \multicolumn{4}{|c|}{ Table 6} \\
\hline \multicolumn{4}{|c|}{$\begin{array}{l}\text { MODERATING EFFECTS OF STRESS } \\
\text { ON DEPRESSED MOOD: } \\
\text { REGRESSION ANALYSIS }\end{array}$} \\
\hline VARIABLE & $B$ & SE $B$ & $B$ \\
\hline $\begin{array}{l}\text { Stress } \\
\text { Group }\end{array}$ & 0.31 & 0.09 & $0.28^{*}$ \\
\hline $\begin{array}{l}\text { (Housed vs Homeless) } \\
\text { Stress } \times \text { Group }\end{array}$ & $\begin{array}{l}0.82 \\
0.10\end{array}$ & $\begin{array}{l}3.01 \\
0.09\end{array}$ & $\begin{array}{l}0.07 \\
0.28\end{array}$ \\
\hline$" p<.001$. & & & \\
\hline
\end{tabular}


grappling, it also highlights the potential importance of traumatic events such as domestic violence and family alcohol use, both of which were reported more frequently in the homeless sample, a finding consistent with other work (Ingram, Corning, \& Schmidt, 1996; Salomon, Bassuk, \& Brooks, 1996; Toro et al., 1995; Wagner \& Perrine, 1994; Weitzman et al., 1992).

As in research on stress, such as that by Turner and colleagues (1995), the present study found that stress, for the homeless group, was related to higher levels of depression. Such findings are consistent with Goodman et al.'s hypothesis that homelessness may be an acute traumatic crisis in which any change in level of experienced stress is associated with increased depressive symptoms. This association is consistent with the findings in coping research that an environment of increased stress precipitates an elevation in coping efforts (Holohan \& Moos, 1987a). In this light, it is interesting that the current sample of homeless women also reported higher levels of both active-cognitive and avoidant coping.

The existence of higher levels of avoidant coping among the homeless sample raises important questions about direction of effects. The use of such stress reduction strategies as refusing to believe the problem exists or imbibing alcohol to reduce tension may put families at greater risk of becoming homeless. Weitzman et al. (1992) found that mental health hospitalization and substance abuse problems predicted requests for shelter assistance among samples of low-income families. While substance abuse itself was not assessed in the current study, the higher rates of avoidant coping in the homeless sample may have been a contributing risk for this group, mediating previously documented relationships between mental health problems and risk of homelessness.

On the other hand, the condition of homelessness itself may lead to greater use of avoidant coping. Findings in stress re- search such as that by Dill, Feld, Martin, Beukema, and Belle (1981) have suggested that for chronically stressed samples such as low-income mothers, the best coping strategy may not always be possible. The fact that the present sample of homeless mothers reported higher levels of stress may mean that these women have to deal with more uncontrollable problems that restrict their range of coping options and force greater reliance on avoidant strategies, despite greater costs. As one homeless mother in the current study said, "I just started smoking since I've been here. I told my kids [when they asked] 'Mom, why'd you start smoking again?' My voice goes and my mouth gets really dry. I says, 'Well, for one, I ran out of fingernails, and for two, stress is starting to show visually, you know, and this time I had to substitute something, which was a bad substitute, but..." Fondacaro and Moos (1989) found an association between negative life events and emotional discharge coping (similar to to avoidant coping as measured in the current study), and hypothesized that less effective coping may have to do with the psychosocial context in which the individual is operating: "Cumulative or persistent stressors may gradually erode an individual's coping resources. Negative life events and role strains can lead to less effective coping responses, which then lead to depression" ( $p$. 331). This view also fits Goodman et al.'s (1991) conceptualization of the traumatic effects of homelessness: that learned helplessness and depression result from being homeless and having diminished opportunities for control of various aspects of one's life. The present study's finding that increased use of avoidant coping was associated with more depressive symptoms is consistent with these earlier findings.

A number of limitations to the current study place constraints on the conclusions that can be drawn. First, future work using prospective longitudinal designs is needed to clarify whether the increased depression 
found among the homeless was a cause or an effect of homelessness. Second, the exclusive reliance on self-report measures restricts the data to information that participants were willing to share. Third, given the prescreening by the shelter staff, the sample of homeless mothers probably represented a higher functioning segment of this population. Finally, the sampling was limited by the fact that exact response rates for the two groups could not be calculated. It is important that future studies with larger numbers of participants test more complex models of coping by using other mediating factors (e.g., attributional processes) and more varied outcome measures (e.g., substance abuse).

Notwithstanding these limitations, knowledge about this segment of the population contributes to an understanding of homelessness among families. The current research also adds to our information about variability among homeless mothers, and may thus offer clues about strengths and skills that can benefit others who are doing less well.

The homeless women in the sample appeared to experience stress and depression that resulted from levels of financial, intimate relationship, and other problems greater even than those found among the housed families living in poverty. Some of the differences in depressed mood may be accounted for by differences in stress exposure and coping resources. However, homeless mothers reported using a variety of coping strategies that were not significantly different from those used by the housed low-income women; if anything, they used more problem-oriented strategies. This points to areas of competence, as well as of difficulty, and demonstrates the existence of multiple responses and outcomes within groups of homeless families. This diversity needs to be taken into account in future studies, which should examine stress resistance, as well as problems. Indeed, coping strategies and their use may be a good target for intervention.
The causes of homelessness are complex, and its amelioration will require changes at many levels. Increased access by homeless families to resources such as jobs and housing is necessary. So, too, are individually tailored interventions for those whose depression or substance use hinder their ability to take advantage of opportunities. High levels of stress in parents also have an impact on their children, which points to a need for the development of services that address both children's needs and the functioning of the family unit (Koblinsky, Morgan, \& Anderson, 1997). Additional research within the framework of a stress and coping model should help in further identifying characteristics of stress resistant individuals. Greater understanding of such characteristics can augment the design of service models to assist those who experience particular or extreme difficulties in coping.

\section{REFERENCES}

Aldwin, C.M. (1994). Stress, coping, and development. New York: Guilford Press.

Avison, W.R. \& Gotlib, I.H. (1994). Stress and mental health: Contemporary issues and prospects for the future. New York: Plenum Press.

Banyard, V.L. (1995). Taking another route: Daily survival narratives from mothers who are homeless. American Journal of Community Psychology. 23, 871-891.

Banyard, V.L. \& Graham-Bermann, S.A. (1993). Can women cope? A gender analysis of theories of coping with stress. Psychology of Women Quarterly, 17, 303-318.

Banyard, V.L. \& Graham-Bermann, S.A. (1995). Building and empowerment policy paradigm: Self-reported strengths of homeless mothers. American Journal of Orthopsychiatry, 65, $479-491$.

Baron, R.M. \& Kenny, D.A. (1986). The moderatormediator variable distinction in social psychological research: Conceptual, strategic, and statistical considerations. Journal of Personality and Social Psychology, 51, 1173-1182.

Bassuk, E.L. (1993a). Homeless women-economic and social issues: Introduction. American Journal of Orthopsychiatry, 63, 337-339.

Bassuk, E.L. (1993b). Social and economic hardships of homeless and other poor women. American Journal of Orthopsychiatry, 63, 340-347.

Belle, D. (1982). Lives in stress. Beverly Hills, CA: Sage Publications.

Belle, D. (1990). Poverty and women's mental health. American Psychologist, 45, 385-389.

Billings, A.G., \& Moos, R.H. (1981). The role of 
coping responses and social resources in attenuating the stress of life events. Journal of Behavioral Medicine, 4, 139-157.

Brooks, M.G. \& Buckner, J.C. (1996). Work and welfare: Job histories, barriers to employment, and predictors of work among low-income single mothers. American Journal of Orthopsychiatry, 66, 526-537.

Buckner, J.C., Bassuk, E.L., \& Zima, B.T. (1993). Mental health issues affecting homeless women: Implications for intervention. American Journal of Orthopsychiatry, 63, 385-399.

Burt, M.R., \& Cohen, B.E. (1989). Differences among homeless single women, women with children, and single men. Social Problems, 36, 508-524.

Comstock, G.W. \& Helsing, K.J. (1976). Symptoms of depression in two communities. Psychological Medicine, 6, 551-563.

DiBlasio, F.A., \& Belcher, J.R. (1992). Keeping homeless families together: Examining their needs. Children and Youth Services Review, 14, 427-438.

DiBlasio, F.A., \& Belcher, J.R. (1995). Gender differences among homeless persons: Special services for women. American Journal of Orthopsychiatry, 65, 131-137.

Dill, D., Feld, E., Martin, J., Beukema, S., \& Belle, D. (1980). The impact of the environment on the coping efforts of low-income mothers. Family Relations, 29, 503-509.

Folkman, S., \& Lazarus, R.S. (1980). An analysis of coping in a middle-aged community sample. Journal of Health and Social Behavior, 21, 219-239.

Fondacaro, M.R., \& Moos, R.H. (1989). Life stressors and coping: A longitudinal analysis among depressed and nondepressed adults. Journal of Community Psychology, 17, 330-340.

Goldsmith, D.F., \& Rogoff, B. (1995). Sensitivity and teaching by dysphoric and nondysphoric women in structured versus unstructured situations. Developmental Psychology, 31, 388-394.

Goodman, L., Saxe, L., \& Harvey, M. (1991). Homelessness as psychological trauma: Broadening perspectives. American Psychologist, 46, 1219-1225.

Hagen, J.L. (1987). Gender and homelessness. Social Work, 32, 312-316.

Hausman, B., \& Hammen, C. (1993). Parenting in homeless families: The double crisis. American Journal of Orthopsychiatry, 63, 358-369.

Hobfoll, S.E. (1989). Conservation of resources: A new attempt at conceptualizing stress. American Psychologist, 44, 513-524.

Holahan, C.J., \& Moos, R.H. (1987a). Personal and contextual determinants of coping strategies. Journal of Personality and Social Psychology, 52, 946-955.

Holahan, C.J., \& Moos, R.H. (1987b). Risk, resistance, and psychological distress: A longitudinal analysis with adults and children. Journal of $A b$ normal Psychology, 96, 3-13.

Holahan, C.J., \& Moos, R.H. (1990). Life stressors, resistance factors, and improved psychological functioning: An extension of the stress resistance paradigm. Journal of Personality and Social Psy. chology, 58, 909-917.
Ingram, K.M., Corning, A.F., \& Schmidt, L.D. (1996). The relationship of victimization experiences to psychological well-being among homeless women and low-income housed women. Journal of Counseling Psychology, 43, 218-227.

Koblinsky, S.A., Morgan, K.M., \& Anderson, E.A. (1997). African-American homeless and lowincome housed mothers: Comparison of parenting practices. American Journal of Orthopsychiatry. $67,37-47$.

Koegel, P., Burnam, M.A., \& Farr, R.K. (1990). Subsistence adaptation among homeless adults in the inner city of Los Angeles. Journal of Social Issues, 46, 83-107.

Lazarus, R.S., \& Folkman, S. (1984). Coping and adaptation. In W.D. Gentry (Ed.), Handbook of behavioral medicine (pp. 282-325). New York: Guilford Press.

Link, B.G., Susser, E., Stueve, A., Phelan, J., Moore, R.E., \& Struening, E. (1994). Lifetime and fiveyear prevalence of homelessness in the United States. American Journal of Public Health, 84, 1907-1912.

Lykes, M.B. (1983). Discrimination and coping in the lives of black women: Analyses of oral history data. Journal of Social Issues, 39, 79-100.

Masten, A.S., Miliotis, D., Graham-Bermann, S.A., Ramirez, M., \& Neeman, J. (1993). Children in homeless families: Risks to mental health and development. Journal of Consulting and Clinical Psychology, 61, 335-343.

McAdoo, H.P. (1986). Strategies used by black single mothers against stress. In M.C. Simms \& J. Malveaux (Eds.), Slipping through the cracks: The status of black women (pp. 153-166). New Brunswick, NJ: Transaction Books.

Milburn, N., \& D'Ercole, A. (1991). Homeless women: Moving toward a comprehensive model. American Psychologist, 46, 1161-1169.

Monroe, S.M., \& McQuaid, J.R. (1994). Measuring life stress and assessing its impact on mental health. In W.R. Avison \& I.H. Gotlib (Eds.), Stress and mental health: Contemporary issues and prospects for the future (pp. 43-73). New York: Plenum Press.

Moos, R.H., Cronkite, R.C., \& Finney, J.W. (1984). Health and Daily Living Form Manual (2nd ed.). Center for Health Care Evaluation, Stanford University Medical Center, Palo Alto, CA.

North, C.S., \& Smith, E.M. (1993). A comparison of homeless men and women: Different populations, different needs. Community Mental Health Journal, 29, 423-431.

Olson, S.L., Kieschnick, E., Banyard, V., \& Ceballo, R. (1994). Socioenvironmental and individual correlates of psychological adjustment in low-income single mothers. American Journal of Orthopsychiatry, 64, 317-331.

Pearlin, L.I. (1989). The sociological study of stress. Journal of Health and Social Behavior, 30, 241-256.

Pearlin, L.I., \& Schooler, C. (1978). The structure of coping. Journal of Health and Social Behavior, $19,2-21$.

Pedhazur, E.J., \& Schmelkin, L.P. (1991). Measure- 
ment, design, and analysis: An integrated approach. Hillsdale, NJ: Erlbaum.

Peters, M.F., \& Massey, G. (1983). Mundane extreme environmental stress in family stress theories: The case of black families in white America. Marriage and Family Review, 6, 193-218.

Robertson, M.J. (1991). Homeless women with children: The role of alcohol and other drug abuse. American Psychologist, 46, 1198-1204.

Radloff, L.S. (1977). The CES-D scale: A self-report depression scale for research in the general population. Applied Psychological Measurement, I, $385-401$.

Rescorla, L., Parker, R., \& Stolley, P. (1991). Ability, achievement, and adjustment in homeless children. American Journal of Orthopsychiatry, 6I, 210-220.

Roth, D., Toomey, B.G., \& First, R.J. (1992). Gender, racial, and age variations among homeless persons. In M.J. Robertson \& M. Greenblatt (Eds.), Homelessness: A National Perspective (pp.199-211). New York: Plenum Press.

Salomon, A., Bassuk, S.S., \& Brooks, M.G. (1996). Patterns of welfare use among poor and homeless women. American Journal of Orthopsychiatry, 66, 510-525.

Shinn, M., \& Weitzman, B.C. (1990). Research on homelessness: An introduction. Journal of Social Issues, 46, 1-11.

Stone, A.A., \& Neale, J.M. (1984). New measure of daily coping: Development and preliminary results. Journal of Personality and Social Psychology, 46, 892-906.

Teti, D.M., Gelfand, D.M., Messinger, D.S., \& Is- abella, R. (1995). Maternal depression and the quality of early attachment: An examination of infants, preschoolers, and their mothers. Developmental Psychology, 31, 364-376.

Toro, P.A., Bellavia, C.W., Daeschler, C.V., Owens, B.J., Wall, D.D., Passero, J.M., \& Thomas, D.M. (1995). Distinguishing homelessness from poverty: A comparative study. Journal of Consulting and Clinical Psychology, 63, 280-289.

Turner, R.J., Wheaton, B., \& Lloyd, D.A. (1995). The epidemiology of social stress. American Sociological Review, 60, 104-125.

Wagner, J.K., \& Perrine, R.M. (1994). Women at risk for homelessness: Comparison between housed and homeless women. Psychological Reports, 75, 1671-1678.

Watts-Jones, D. (1991). Toward a stress scale for African-American women. Psychology of Women Quarterly, 14, 271-275.

Weissman, M.M., Sholomskas, D., Pottenger, M., Prusoff, B.A., \& Locke, B.Z. (1977). Assessing depressive symptoms in five psychiatric populations: A validation study. American Journal of Epidemiology, 106, 203-214.

Weitzman, B.C., Knickman, J.R., \& Shinn, M. (1992). Predictors of shelter use among lowincome families: Psychiatric history, substance abuse, and victimization. American Journal of Public Health, 82, 1547-1550.

Wheaton, B. (1994). Sampling the stress universe. In W.R. Avison \& I.H. Gotlib (Eds.), Stress and mental health: Contemporary issues and prospects for the future (pp.77-114). New York: Plenum Press. 